\title{
Serum concentrations of 25-hydroxyvitamin $D$ and its association with bone mineral density and serum parathyroid hormone levels during winter in urban males from Guiyang, Southwest China
}

\author{
Qiao Zhang, Lixin Shi*, Nianchun Peng, Shujing Xu, Miao Zhang, Song Zhang, Hong Li, Huijun Zhuang, \\ Mingxian Gong, Danrong Wu and Rui Wang \\ Department of Endocrinology and Metabolism, Affiliated Hospital of Guiyang Medical College, Guiyang, Guizhou 550004, \\ People's Republic of China, China
}

(Submitted 4 September 2014 - Final revision received 17 November 2015 - Accepted 8 December 2015 - First published online 4 February 2016)

\section{Abstract}

Serum vitamin D (25-hydroxyvitamin D (25OHD)) may influence serum parathyroid hormone (PTH) levels and bone mineral density (BMD). In the present study, we assessed serum 25OHD concentration and its association with PTH and BMD in urban males from Guiyang (N26.57 $)$, the capital city of Guizhou province, Southwest China. We recruited 634 males aged $>20$ years from the Guiyang Health Measures Survey, and stratified them into three groups according to age: young (20-39 years), middle aged (40-59 years) and older (60-79 years). We measured serum concentrations of 25OHD, PTH levels and BMD of the lumbar spine (L1-L4), femoral neck and total hip. In addition, we also explored the relationship between $25 \mathrm{OHD}$ and lifestyle, socio-economic characteristics and medical history by applying covariance analysis and locally weighted regression plots. The results showed that serum $25 \mathrm{OHD}$ was $<50 \mathrm{nmol} / 1$ in $59 \cdot 3 \%$ of the subjects and $>75 \mathrm{nmol} / 1$ in $12 \cdot 6 \%$ of the subjects. Higher level of serum PTH was detected in relation to lower concentrations of serum $25 \mathrm{OHD}$ up to $50 \mathrm{nmol} / \mathrm{l}$. A negative correlation between serum 25OHD and PTH concentrations was observed $(r-0 \cdot 207, P=0 \cdot 003)$. Mean concentration of serum PTH increased gradually and plateaued while concentrations of serum $25 \mathrm{OHD}$ decreased to $50 \mathrm{nmol} / \mathrm{l}$. Gradual increase in serum PTH was observed as $25 \mathrm{OHD}$ concentration was $<25 \mathrm{nmol} / 1(P=0.004)$. BMD values at all sites were greater in the higher serum 25 OHD concentration group. This study shows that low concentrations of serum 25OHD were common in males, and bone health was likely to be improved when serum $25 \mathrm{OHD}$ values were between 30 and $50 \mathrm{nmol} / \mathrm{l}$.

\section{Key words: Serum 25-hydroxyvitamin D: Parathyroid hormone: Bone mineral density: Southwest China}

Vitamin D deficiency is an increasingly recognised global health problem $^{(1)}$. Studies have shown that vitamin D plays important roles in regulating $\mathrm{Ca}$ and $\mathrm{P}$ metabolism and in maintaining normal bone mineral salts in the human body ${ }^{(2)}$.

Vitamin D deficiency increases the risks of osteomalacia, fracture and fall ${ }^{(3,4)}$. Vitamin $\mathrm{D}$ and $\mathrm{Ca}$ supplementation decrease the incidence of hip fracture and other non-vertebral fractures $^{(5,6)}$. However, the proper concentrations of serum 25-hydroxyvitamin D (25OHD) that are required for adequate bone health have been debated and remain controversial.

Serum 25OHD concentrations associated with plateauing of serum parathyroid hormone (PTH) vary between studies. A limited number of studies that have investigated vitamin $\mathrm{D}$ supplementation indicate that the serum 25OHD concentrations leading to suppression of PTH are about $50 \mathrm{nmol} / \mathrm{l}^{(7,8)}$. However, other studies have shown that PTH reaches a nadir at higher serum $25 \mathrm{OHD}$ concentrations, approximately $75-80 \mathrm{nmol} / \mathrm{l}^{(9,10)}$. The US population-based National Health and Nutrition Examination Survey III study shows that BMD of the hip is increased with a higher serum $25 \mathrm{OHD}$ of up to $50^{(11)}$ or $80 \mathrm{nmol} / \mathrm{l}^{(9)}$. The relationships between serum $25 \mathrm{OHD}$, PTH and bone density status are often inconsistent and influenced by predictors such as seasonality, age, ethnicity, BMI, physical activity levels and genetic factors $^{(12-14)}$. Therefore, it is necessary to better understand the contributions of serum $25 \mathrm{OHD}$ concentrations in order to determine factors that may influence the status of bone density. The present study aims to estimate whether serum 25OHD concentrations are associated with serum PTH and BMD in urban males living in Guiyang, Southwest China.

\section{Methods \\ Study sample}

We performed a cross-sectional study in a community, in Guiyang, Southwest China, from November 2009 to February 2010. The study population was from the Guiyang Health Measures Survey, which has been set up as a prospective

Abbreviations: 25OHD, 25-hydroxyvitamin D; Cr, creatinine; PTH, parathyroid hormone.

* Corresponding author: L. Shi, fax +86 851685 3369, email slx1962@medmail.com.cn 
observational study aiming to evaluate chronic diseases in Guiyang population. In brief, a random sample of men aged between 20 and 79 years and who lived in Guiyang City $\left(26.57^{\circ} \mathrm{N}\right)$ for more than 10 years were invited to participate by examination notice or a home visit. After a main interview ( $n$ 700), participants were invited to the hospital of Zaiji Community, where blood samples were collected from 634 subjects. Serum concentrations of 25OHD, PTH, Ca, P and creatinine $(\mathrm{Cr})$ were measured in 634 subjects. BMD measurements of the lumbar spine, femoral neck and total hip were obtained in a sub-sample including 505 participants. The 634 subjects were stratified into three groups according to their age: 346 subjects in the young age group (20-39 years), 182 subjects in the middle-aged group (40-59 years) and 106 subjects in older age group (60-79 years). All the analyses were conducted by intensively trained and supervised interviewers, and were tape-recorded to monitor the quality of the data. Informed consent was obtained from all the subjects. The study protocol has been approved by the local Medical Ethics Committee of the Guiyang Medical College.

\section{Clinical and biochemical measurements}

All the subjects completed a standard questionnaire on socioeconomic characteristics (e.g. education, occupation), lifestyle factors (e.g. outdoor activity, smoking status, alcohol consumption) and medical history. Educational status was assessed by asking the subjects for the highest educational level completed, and ranged from primary school to university. Smoking status and alcohol consumption were classified as 'never' and 'current' (smoking or drinking regularly in the past 6 months). Medical history included chronic obstructive pulmonary disease, chronic renal disease, CVD, stroke, peripheral arterial disease, diabetes, malignant neoplasms and joint disorders including osteoarthritis and rheumatoid arthritis. All the participants completed anthropometrical measurements with the assistance of trained staff using standard protocols. BMI was calculated as weight in kilograms divided by height in metres squared $\left(\mathrm{kg} / \mathrm{m}^{2}\right)$. Exclusion criteria were as follows: presence of known bone disease, liver or renal disease (values $\geq 2 \times$ upper limit of normal for aspartate aminotransferase, alanine aminotransferase, $\gamma$-glutamyl transpeptidase, urea, $\mathrm{Cr}$ and uric acid resulted in exclusion), serious diseases (e.g. cancer) and use of medication influencing bone metabolism (excluding $\mathrm{Ca}$ and vitamin D supplementation). Blood samples were obtained in the morning after fasting for 8-10 h and were immediately centrifuged; the separated serum samples were frozen for $25 \mathrm{OHD}$ and PTH measurements. Serum 25OHD concentrations and PTH concentrations were measured by automatic RIA (DiaSorin Inc.). The lower and upper detection limits of serum 25OHD concentrations and PTH concentrations were $4 \cdot 1-149 \cdot 1 \mathrm{nmol} / 1$ and $1 \cdot 37-5.68 \mathrm{pmol} / 1$, respectively. The inter-assay $\mathrm{CV}$ of serum $25 \mathrm{OHD}$ and PTH were 8.8 and $2.4 \%$, respectively. The intra-assay $\mathrm{CV}$ of serum $25 \mathrm{OHD}$ and $\mathrm{PTH}$ were 11.1 and $4.9 \%$, respectively. Serum $\mathrm{Ca}, \mathrm{P}$ and $\mathrm{Cr}$ levels were measured using an automated biochemical analyzer (Olympus AU5400; Olympus). The analyses were carried out at the Endocrine Laboratory of the Guiyang Medical College Center.

\section{Bone mineral density measurement and definition of} osteoporosis

The dual-energy X-ray absorption scans were obtained using a lunar prodigy scanner (GE Medical System Co. Ltd). The lumbar spine and left hip were scanned. BMD $\left(\mathrm{g} / \mathrm{cm}^{2}\right)$ of the femoral neck, total hip and lumbar spine (L1-L4) were measured. Osteoporosis was defined according to the WHO classification ${ }^{(15)}$.

\section{Statistical analyses}

Statistical analyses were performed using SPSS 13.0 for Windows (SPSS). Continuous variables were presented as mean values and standard deviations except for skewed variables, which were presented as medians and interquartile ranges. Categorical variables were expressed as numbers (proportions). We used ANCOVA, which was adjusted for potential confounders (such as age, educational status, Cr levels, chronic disease, smoking status). Serum 25OHD (nmol/l) was presented as quartiles: quartile 1, $<25 \mathrm{nmol} / \mathrm{l}$; quartile 2, $25-<50 \mathrm{nmol} / \mathrm{l}$; quartile 3, $50-<75 \mathrm{nmol} / \mathrm{l}$; and quartile $4, \geq 75 \mathrm{nmol} / 1$. Subsequently, locally weighted regression smoothing (LOESS) plots with $95 \%$ CI were obtained in S-Plus (MathSoft Inc.) to investigate the relationship between serum 25OHD and various outcome measures. Differences among groups were tested by one-way ANOVA and post hoc comparisons were performed using Bonferroni correction. Comparisons between categorical variables were performed using the $\chi^{2}$ test. The unadjusted and multivariate-adjusted logistic regression analyses were used to assess the risk of potential confounders (as age, educational status, Cr levels, chronic disease, smoking status) in relation to each quartile increase in serum $25 \mathrm{OHD}$ concentration. All the statistical tests were two-sided, and a $P$ value $<0.05$ was considered to be statistically significant.

\section{Results}

Baseline characteristics of the population are described in Table 1. Mean values of serum 25OHD, PTH and BMI were significantly higher in the middle-aged and older-aged groups than in the young-aged group. As expected, serum $\mathrm{Ca}$ and $\mathrm{P}$ concentrations and BMD values of the femoral neck and total hip measurements were significantly higher in the young-aged group than in the middle-aged and older-aged groups (Table 2). A negative correlation between serum 25OHD and PTH concentrations was observed in all subjects $(r-0 \cdot 207, P=0 \cdot 003)$. Table 3 shows values of serum $\mathrm{Ca}, \mathrm{P}, \mathrm{PTH}, \mathrm{BMD}$ among different $25 \mathrm{OHD}$ concentration groups, as well as different age groups in the study. Serum $25 \mathrm{OHD}$ was $<25 \mathrm{nmol} / 1$ in $16.1 \%$ of the subjects, $<50 \mathrm{nmol} / 1$ in $59.3 \%$ of the subjects, $<75 \mathrm{nmol} / 1$ in $87.4 \%$ of the subjects and $>75 \mathrm{nmol} / 1$ in $12.6 \%$ of the study participants. In all age groups, the mean serum concentration of PTH was negatively correlated with $25 \mathrm{OHD}$. In contrast, serum $\mathrm{Ca}$ and $\mathrm{P}$ concentrations did not differ significantly from each group. All the BMD values were greater in the higher serum 25OHD groups, whereas only total hip in the young age group, total hip and L1-L4 $(P=0 \cdot 041,0 \cdot 036)$ in the middle-aged group and total hip in the older age group $(P=0.024)$ showed statistical significance $(P=0 \cdot 023)$. 
Univariate analyses, after adjusting for age, educational status, Cr levels, chronic disease and smoking status, have been described in the Methods section. Our results showed that a significant positive association was found between $25 \mathrm{OHD}$ concentrations and BMD of the total hip $(r 0 \cdot 289, P=0 \cdot 022)$ and L1-L4 $(r 0.179, P=0.031)$ in the young group, of the total hip

Table 1. Baseline characteristics

(Numbers and percentages; mean values and standard deviations) ${ }^{*}$

\begin{tabular}{|c|c|c|}
\hline Variables & $n$ & $\%$ \\
\hline \multicolumn{3}{|l|}{ Age (years) } \\
\hline 20 & 115 & $18 \cdot 1$ \\
\hline 30 & 148 & $23 \cdot 3$ \\
\hline 40 & 135 & $21 \cdot 3$ \\
\hline 50 & 118 & $18 \cdot 6$ \\
\hline 60 & 60 & 9.5 \\
\hline 70 & 58 & $9 \cdot 2$ \\
\hline $20-79$ & 634 & 100 \\
\hline Alcohol drinker & 376 & $59 \cdot 3$ \\
\hline Smoker & 206 & $32 \cdot 5$ \\
\hline Drinking milk & 118 & $18 \cdot 6$ \\
\hline Ca supplementation & 51 & 8.0 \\
\hline Vitamin D supplementation & 15 & 2.4 \\
\hline \multicolumn{3}{|l|}{ Outdoor activity } \\
\hline$\leq 30 \mathrm{~min} / \mathrm{d}$ & 377 & $59 \cdot 5$ \\
\hline $30-60 \mathrm{~min} / \mathrm{d}$ & 146 & 23.0 \\
\hline$\geq 60 \mathrm{~min} / \mathrm{d}$ & 109 & $17 \cdot 2$ \\
\hline \multicolumn{3}{|l|}{ Education (years) } \\
\hline $0-6$ & 51 & 8.0 \\
\hline $7-9$ & 144 & $22 \cdot 7$ \\
\hline $10-12$ & 142 & $22 \cdot 4$ \\
\hline \multirow[t]{2}{*}{$\geq 13$} & 297 & $46 \cdot 8$ \\
\hline & Mean & $\mathrm{SD}$ \\
\hline BMI $\left(\mathrm{kg} / \mathrm{m}^{2}\right)$ & $24 \cdot 1$ & $3 \cdot 3$ \\
\hline Waist circumference $(\mathrm{cm})$ & 85.4 & 8.9 \\
\hline Waist:hip ratio & 0.9 & 0.1 \\
\hline Total Ca $(\mathrm{mmol} / \mathrm{l})$ & 2.4 & 0.2 \\
\hline $\mathrm{P}(\mathrm{mmol} / \mathrm{l})$ & $1 \cdot 0$ & 0.2 \\
\hline Creatinine $(\mu \mathrm{mol} / \mathrm{l})$ & $74 \cdot 6$ & $12 \cdot 7$ \\
\hline $250 \mathrm{OHD}(\mathrm{nmol} / \mathrm{l})$ & $50 \cdot 0$ & $20 \cdot 3$ \\
\hline PTH (pmol/l) & $3 \cdot 1$ & $1 \cdot 1$ \\
\hline
\end{tabular}

25OHD, 25-hydroxyvitamin D; PTH, parathyroid hormone.

* For conversion of $25 \mathrm{OHD}$ from $\mathrm{nmol} / \mathrm{l}$ to $\mathrm{ng} / \mathrm{ml}$, divide by 2.496 . For conversion of PTH from $\mathrm{pmol} / \mathrm{l}$ to $\mathrm{pg} / \mathrm{ml}$, multiply by 11.1 . Serum $25 \mathrm{OHD}$ was assessed in 634 subjects and PTH was assessed in 516 subjects.
( $r 0.157, P=0.035)$ and the femoral neck $(r 0 \cdot 149, P=0.038)$ in the middle-aged group and of the total hip $(r 0.154, P=0.04)$, femoral neck $(r 0.254, P=0 \cdot 017)$ and lumbar spine (L1-L4) ( $r 0 \cdot 260, P=0 \cdot 011$ ) in the older age group in our study.

The relationships among 25OHD, BMD and PTH are shown in Fig. 1. The LOESS plots with $95 \%$ CI, which were adjusted for age, BMI, Cr levels and smoking status, are also shown in Fig. 2. We found that the relationship between 25OHD and BMD of the total hip and the L1-L4 vertebrae in all groups reached a plateau in the range of $30-50 \mathrm{nmol} / \mathrm{l}$ as shown in Fig. 2(a)-(d).

\section{Discussion}

It is well established that vitamin D deficiency causes secondary hyperparathyroidism and bone loss. The results of the Longitudinal Ageing Study in Amsterdam confirmed that low serum $25 \mathrm{OHD}$ concentrations are associated with an increase in serum PTH, increased bone turnover and lower BMD ${ }^{(10)}$. However, the threshold values at which serum PTH and bone resorption started to increase and BMD started to decrease were highly variable in different studies.

In our study, compared with participants with higher serum 25OHD concentrations, those with lower 25OHD concentrations combined with higher serum PTH concentrations were older and were less commonly current alcohol consumers and current smokers. Comparatively, Li et al. ${ }^{(16)}$ investigated the associations of serum $25 \mathrm{OHD}$ concentrations with hypertension among 1420 participants, aged $20-83$ years in Dali $\left(25^{\circ} \mathrm{N}\right)$. In their study, the mean concentration of $25 \mathrm{OHD}$ was $22.0 \mathrm{ng} / \mathrm{ml}$ $(55 \mathrm{nmol} / \mathrm{l})$. Moreover, another study showed that 939 Chinese old men in Hong Kong $\left(22^{\circ} \mathrm{N}\right)^{(17)}$ had a mean serum $25 \mathrm{OHD}$ concentration of $77.9 \mathrm{nmol} / \mathrm{l}$. The different levels of $25 \mathrm{OHD}$ that were observed among the three Chinese studies may have resulted from the different study populations, geography and season. In the present study, serum PTH reached a plateau at lower values of serum $25 \mathrm{OHD}$ of $50 \mathrm{nmol} / 1$, which may imply that the optimal serum 25OHD concentration is approximately $50 \mathrm{nmol} / 1$ for bone health. Furthermore, a significant positive association between 25OHD concentrations and BMD of different parts was found, and BMD increased to a higher value

Table 2. Mean values of BMI, serum 25-hydroxyvitamin D (25OHD), parathyroid hormone (PTH), calcium, phosphorus and bone mineral density (BMD) in different age groups

(Mean values and standard deviations)*

\begin{tabular}{|c|c|c|c|c|c|c|}
\hline \multirow[b]{2}{*}{ Variables } & \multicolumn{2}{|c|}{ Young age ( $n$ 346) } & \multicolumn{2}{|c|}{ Middle aged ( $n$ 182) } & \multicolumn{2}{|c|}{ Older age $(n 106)$} \\
\hline & Mean & SD & Mean & SD & Mean & SD \\
\hline Age (years) & $30 \cdot 9^{c}$ & $5 \cdot 4$ & $49 \cdot 2^{b}$ & $5 \cdot 8$ & 68.9 & $4 \cdot 3$ \\
\hline BMI $\left(\mathrm{kg} / \mathrm{m}^{2}\right)$ & $23 \cdot 6^{b}$ & $3 \cdot 6$ & 24.5 & $3 \cdot 1$ & $24 \cdot 6$ & 2.9 \\
\hline $250 \mathrm{OHD}(\mathrm{nmol} / \mathrm{l})$ & $43 \cdot 6^{b}$ & 23.7 & 58.9 & $23 \cdot 8$ & $55 \cdot 8$ & $21 \cdot 2$ \\
\hline $\mathrm{PTH}(\mathrm{pmol} / \mathrm{l})$ & $2.9^{a}$ & 1.0 & $3 \cdot 1$ & $1 \cdot 2$ & $3 \cdot 2$ & $1 \cdot 2$ \\
\hline Serum Ca $(\mathrm{mmol} / \mathrm{l})$ & $2 \cdot 4^{\mathrm{a}}$ & 0.1 & $2 \cdot 3$ & 0.1 & $2 \cdot 3$ & 0.2 \\
\hline Serum P (mmol/l) & $1 \cdot 1^{\mathrm{a}}$ & 0.2 & $1 \cdot 0^{\mathrm{a}}$ & 0.2 & 0.9 & 0.1 \\
\hline \multicolumn{7}{|l|}{$\operatorname{BMD}\left(\mathrm{g} / \mathrm{cm}^{2}\right)$} \\
\hline Femoral neck & $0.95^{c}$ & 0.12 & $0.88^{b}$ & $0 \cdot 12$ & 0.83 & $0 \cdot 13$ \\
\hline Total hip & $1.00^{c}$ & 0.12 & $0.95^{b}$ & $0 \cdot 13$ & 0.92 & 0.14 \\
\hline Lumbar spine (L1-L4) & $1 \cdot 10$ & 0.12 & $1 \cdot 10$ & $0 \cdot 14$ & 1.07 & 0.20 \\
\hline
\end{tabular}

* For conversion of $25 \mathrm{OHD}$ from $\mathrm{nmol} / \mathrm{l}$ to $\mathrm{ng} / \mathrm{ml}$, divide by $2 \cdot 496$; for conversion of $\mathrm{PTH}$ from $\mathrm{pmol} / \mathrm{l}$ to $\mathrm{pg} / \mathrm{ml}$, multiply by 11.1 .

a $P<0.05,{ }^{\text {b }} P<0.01,{ }^{c} P<0.001$, as compared with the reference category older age group. 
Serum 25-hydroxyvitamin D in urban males

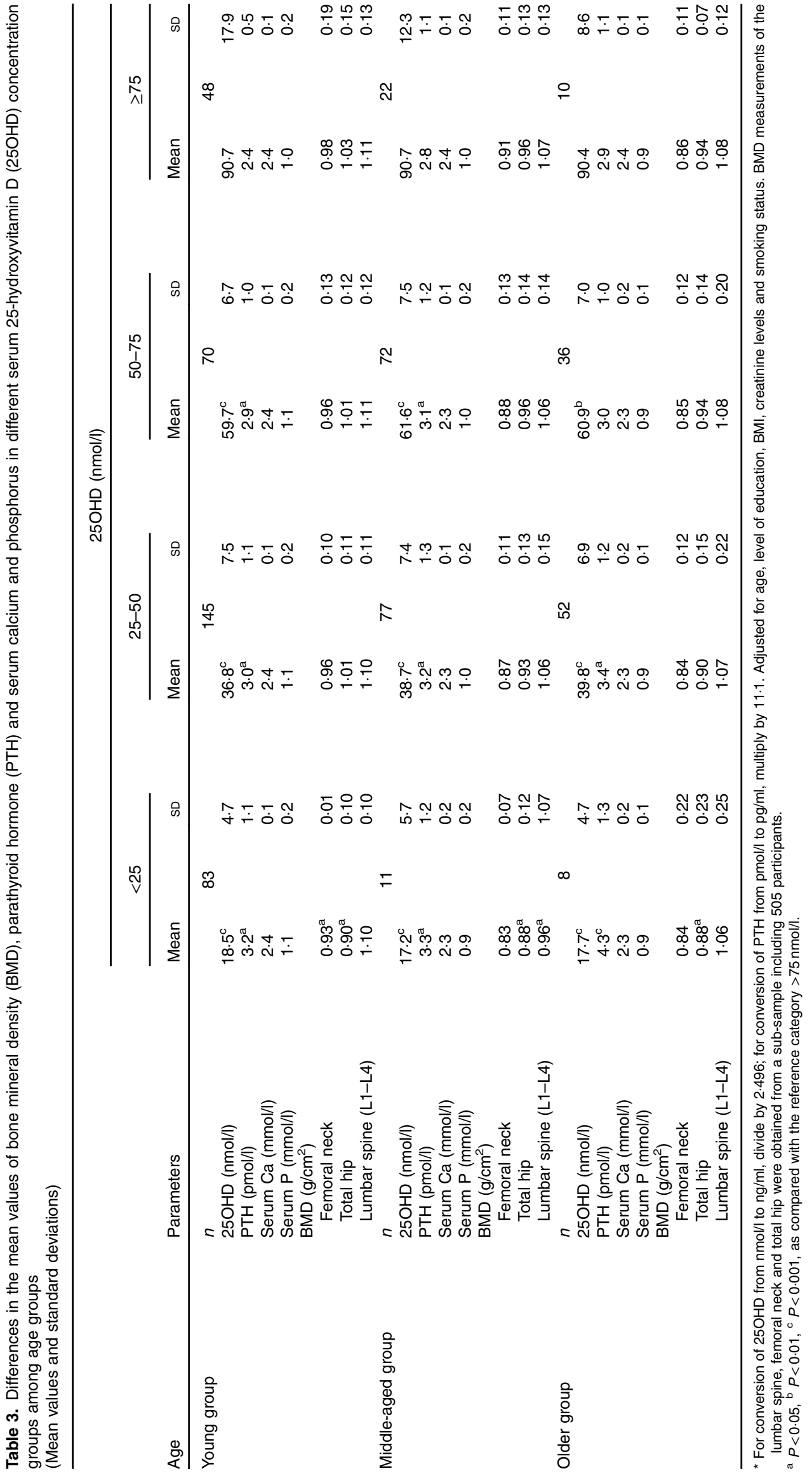


with higher values of $250 \mathrm{HD}$ concentration about $50 \mathrm{nmol} / \mathrm{l}$. These results indicate that the optimal serum threshold of 25OHD for bone health should be between 30 and $50 \mathrm{nmol} / \mathrm{l}$. This study is consistent with previous studies on the relationship of serum 25OHD with BMD as well as serum 25OHD with serum PTH in older subjects ${ }^{(11,18,19)}$ or in the young age and the middle-aged groups ${ }^{(8)}$

Recent discussions have focused on circulating concentrations of $25 \mathrm{OHD}$, which is appropriate. This question is important because it has implications for the prevention of osteoporosis and fractures, and it has relevance for public health strategies, including food fortification with vitamin $\mathrm{D}$ and the use of supplements. The required serum 25OHD concentrations have usually been established by assessing the threshold serum concentration of $25 \mathrm{OHD}$, below which serum

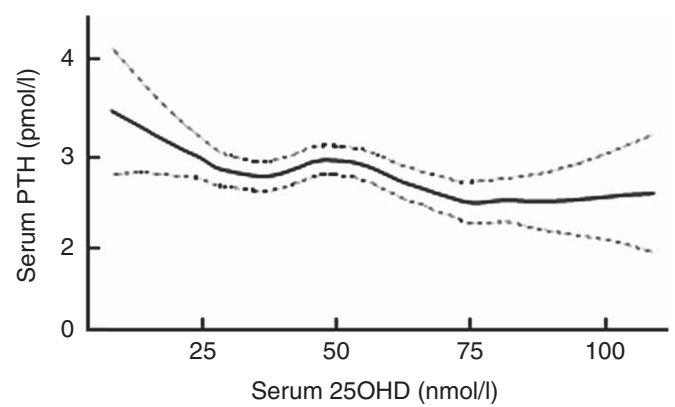

Fig. 1. Relationship between serum 25-hydroxyvitamin $D(25 \mathrm{OHD})$ and parathyroid hormone (PTH) $(P=0.003)$.

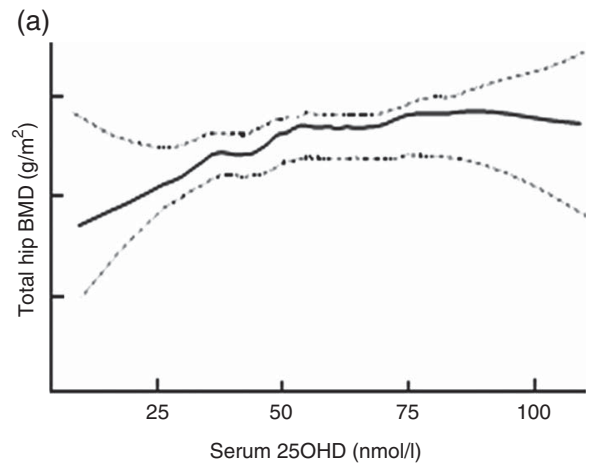

(c)

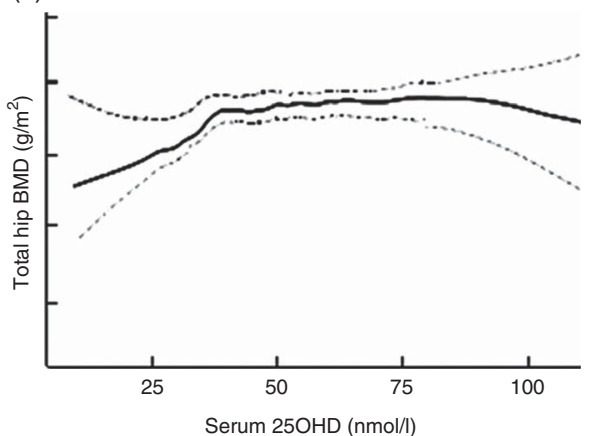

PTH starts to increase. It is suggested that the simultaneous measurement of serum PTH may aid in interpreting the circulating concentrations of serum $25 \mathrm{OHD}$ because of an inverse relationship between them. However, the increase of serum PTH associated with vitamin D deficiency is usually within the normal reference range. In addition, serum PTH has a short half-life and depends on Ca intake, and thus different data sets could lead to different conclusions ${ }^{(13)}$. This threshold concentration of serum $25 \mathrm{OHD}$ may be varied, from $37.5 \mathrm{nmol} / 1$ in a study of American hospital inpatients ${ }^{(20)}, 50 \mathrm{nmol} / 1$ in the vitamin D supplementation study of the $\mathrm{USA}^{(21)}$ and $75 \mathrm{nmol} / \mathrm{l}$ in the French SU.VI.MAX (SUpplémentation en VItamines et Minéraux Anti-oXydants) study ${ }^{(10)}$. The tendency to establish the required serum $25 \mathrm{OHD}$ concentrations by assessing the threshold below which serum PTH starts to rise could lead to the use of almost the upper limit of serum 25OHD concentrations in different data sets as a threshold, establishing the required serum $25 \mathrm{OHD}$ concentration range from 50 to $100 \mathrm{nmol} / \mathrm{l}^{(10,18)}$. In our study, this threshold is in the range of 30 and $50 \mathrm{nmol} / \mathrm{l}$. A significant positive association between $25 \mathrm{OHD}$ concentrations and BMD was observed ${ }^{(22)}$, whereas a threshold of about $80 \mathrm{nmol} / 1$ is found. This concentration represents serum 25OHD concentrations above which BMD increased slowly ${ }^{(23)}$. A review suggests that a desirable serum $25 \mathrm{OHD}$ concentration for optimal health begins at $75 \mathrm{nmol} / \mathrm{l}$, with the optimal concentration being $90-100 \mathrm{nmol} / \mathrm{l}^{(18)}$. Our study yields a lower threshold $(50 \mathrm{nmol} / \mathrm{l})$, which may be due to different assays for determining serum $25 \mathrm{OHD}^{(24)}$, different regions or different race/ethnicity in the context of vitamin $\mathrm{D}$
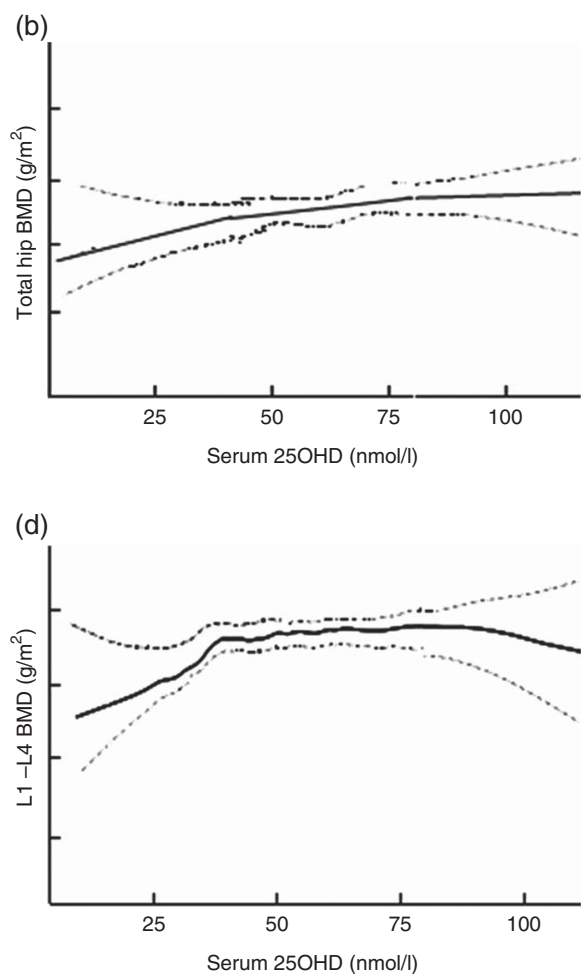

Fig. 2. Relationship between serum 25-hydroxyvitamin D (25OHD) concentrations and bone mineral density (BMD) values of total hip in the young group (a, $r 0 \cdot 189$, $P=0.025$ ), middle-aged group (b, $r 0.149, P=0.040$ ) and older age group (c, $r 0.022, P=0.019$ ), BMD of the lumbar spine (L1-L4) in the middle-aged group (d, $P=0.038)$. All plots are adjusted for level of education, level of BMI, creatinine levels and smoking status. The -..-.. represents the $95 \% \mathrm{Cl}$. 
receptor gene polymorphisms. Different concentrations of serum 25OHD for serum PTH and BMD may also be explained by the extra-renal hydroxylation of $25 \mathrm{OHD}$ to the active metabolite 1,25-dihydroxyvitamin $\mathrm{D}_{3}$ in different organs, because it is known that 1,25-dihydroxyvitamin D is capable of acting via both autocrine and paracrine mechanisms ${ }^{(25)}$.

An important question relates to the optimum oral intake of vitamin $\mathrm{D}$ required to maintain bone health. A review on this matter suggests that all adults aged 50-70 and older than 70 years require vitamin D of at least 15 and $20 \mu \mathrm{g} / \mathrm{d}$ (600 and $800 \mathrm{IU} / \mathrm{d})$, respectively, to maximise bone health and muscle function $^{(26,27)}$. As shown in a meta-analysis on vitamin D status and fracture prevention, a dose of $17 \cdot 5-20 \mu \mathrm{g} / \mathrm{d}(700-800 \mathrm{IU} / \mathrm{d})$ appears to reduce the risk of hip and any non-vertebral fractures in older subjects ${ }^{(28)}$. Therefore, supplementation dose should be $15-20 \mu \mathrm{g} / \mathrm{d}(600-800 \mathrm{IU} / \mathrm{d})$ while sunshine exposure is insufficient. A final executive decision on this question should be made on an individual basis with respect to baseline serum 25OHD concentrations, lifestyle and of course diet.

There are several strengths to our study, including the cohort design, which includes different age groups of male subjects, who are also a representative group of the Southwest China urban population, the combination of serum PTH and measurement of different areas of bone density. However, our study also has its limitations. For example, we measured only serum 25OHD and PTH in a single season. It can be questioned whether serum 25OHD and PTH concentrations measured at a single season reflect the long-term status. In addition, bone turnover markers were not measured.

In conclusion, our study demonstrates that low serum 25OHD concentrations are very common in adult males in the Southwest China urban population. Bone health in the participants is likely to improve when serum $25 \mathrm{OHD}$ is raised to concentrations of $30-50 \mathrm{nmol} / \mathrm{l}$. The implication for our study population is that at least $59.3 \%$ should receive vitamin D supplements because their serum $25 \mathrm{OHD}$ concentrations are $<50 \mathrm{nmol} / \mathrm{l}$.

\section{Acknowledgements}

The authors thank the strong support given to us by the health bureau of Yunyang district in Guiyang, sub-district office and the hospital of Zhaiji community, the biochemistry department, the central lab and the endocrinology department of the affiliated hospital of Guiyang Medical College.

Financial support was received from the Government Foundation of Guizhou Province of China.

Q. Z. drafted the article, acquired the data and wrote the article. N. P. designed the questionnaire and implemented the study. Q. Z., S. X. and M. Z. analysed the data. S. X., M. Z., S. Z., H. L., H. Z., M. G., D. W. and R. W. implemented the research and collected data. L. S. is the guarantor of this work and, as such, had full access to all the data of the study and takes responsibility for the integrity of the data and the accuracy of the data analysis. All the authors approved the final version of the manuscript and performed the literature search.

All the authors declare that they have no conflicts of interest.

\section{References}

1. Adams JS \& Hewison M (2010) Update in vitamin D. J Clin Endocrinol Metab 95, 471-478.

2. Holick MF (2007) Vitamin D deficiency. N Engl J Med 357, 266-281.

3. Bischoff-Ferrari HA, Willett WC, Wong JB, et al. (2009) Prevention of nonvertebral fractures with oral vitamin D and dose dependency: a meta-analysis of randomized controlled trials. Arch Inter Med 169, 551-561.

4. Bischoff-Ferrari HA, Dawson-Hughes B, Staehelin HB, et al. (2009) Fall prevention with supplemental and active forms of vitamin D: a meta-analysis of randomised controlled trials. BMJ 339, b3692.

5. Michael YL, Whitlock EP, Lin JS, et al. (2010) Primary care-relevant interventions to prevent falling in older adults: a systematic evidence review for the U.S. Preventive Services Task Force. Ann Inter Med 153, 815-825.

6. Del Valle HB, Yaktine AL, Taylor CL, et al. (2011) Dietary Reference Intakes for Calcium and Vitamin D. Washington, DC: National Academies Press.

7. Lips P (2004) Which circulating level of 25-hydroxyvitamin D is appropriate? J Stero Biochem Mol Biol 89-90, 611-614.

8. Frost M, Abrahamsen B, Nielsen TL, et al. (2010) Vitamin D status and PTH in young men: a cross-sectional study on associations with bone mineral density, body composition and glucose metabolism. Clin Endocrinol 73, 573-580.

9. Lips P, Hosking D, Lippuner K, et al. (2006) The prevalence of vitamin $\mathrm{D}$ inadequacy amongst women with osteoporosis: an international epidemiological investigation. J Inter Med 260, 245-254.

10. Chapuy MC, Preziosi P, Maamer M, et al. (1997) Prevalence of vitamin $\mathrm{D}$ insufficiency in an adult normal population. Osteoporos Int 7, 439-443.

11. Wicherts IS, van Schoor NM, Boeke AJ, et al. (2007) Vitamin D status predicts physical performance and its decline in older persons. J Clin Endocrinol Metab 92, 2058-2065.

12. Zhao LJ, Zhou Y, Bu F, et al. (2012) Factors predicting vitamin D response variation in non-Hispanic white postmenopausal women. J Clin Endocrinol Metab 97, 2699-2705.

13. Jorde R, Sneve M, Hutchinson M, et al. (2010) Tracking of serum 25-hydroxyvitamin $\mathrm{D}$ levels during 14 years in a population-based study and during 12 months in an intervention study. Am J Epidemiol 171, 903-908.

14. Lucas RM, Ponsonby AL, Dear K, et al. (2013) Vitamin D status: multifactorial contribution of environment, genes and other factors in healthy Australian adults across a latitude gradient. I Stero Biochem Mol Biol 136, 300-308.

15. Kanis JA, Melton LJ 3rd, Christiansen C, et al. (1994) The diagnosis of osteoporosis. J Bone Miner Res 9, 1137-1141.

16. Li L, Yin X, Yao C, et al. (2012) Vitamin D, parathyroid hormone and their associations with hypertension in a Chinese population. PLOS ONE 7, e43344.

17. Chan R, Chan D, Woo J, et al. (2012) Serum 25-hydroxyvitamin D and parathyroid hormone levels in relation to blood pressure in a cross-sectional study in older Chinese men. J Hum Hypertens 26, 20-27.

18. Kuchuk NO, Pluijm SM, van Schoor NM, et al. (2009) Relationships of serum 25-hydroxyvitamin D to bone mineral density and serum parathyroid hormone and markers of bone turnover in older persons. J Clin Endocrinol Metab 94, 1244-1250.

19. Bates CJ, Carter GD, Mishra GD, et al. (2003) In a population study, can parathyroid hormone aid the definition of adequate vitamin D status? A study of people aged 65 years and over from the British National Diet and Nutrition Survey. Osteoporos Int 14, 152-159. 
20. Thomas MK, Lloyd-Jones DM, Thadhani RI, et al. (1998) Hypovitaminosis D in medical inpatients. N Engl J Med 338, 777-783.

21. Malabanan A, Veronikis IE \& Holick MF (1998) Redefining vitamin D insufficiency. Lancet 351, 805-806.

22. Bischoff-Ferrari HA, Dietrich T, Orav EJ, et al. (2004) Positive association between 25-hydroxy vitamin D levels and bone mineral density: a population-based study of younger and older adults. Am J Med 116, 634-639.

23. Bischoff-Ferrari HA, Giovannucci E, Willett WC, et al. (2006) Estimation of optimal serum concentrations of 25-hydroxyvitamin D for multiple health outcomes. Am J Clin Nutr 84, 18-28.

24. Souberbielle JC, Friedlander G, Kahan A, et al. (2006) Evaluating vitamin $\mathrm{D}$ status. Implications for preventing and managing osteoporosis and other chronic diseases. Joint, Bone, Spine 73, 249-253.
25. Bischoff-Ferrari HA (2007) How to select the doses of vitamin $\mathrm{D}$ in the management of osteoporosis. Osteoporos Int 18, 401-407.

26. Holick MF, Binkley NC, Bischoff-Ferrari HA, et al. (2011) Evaluation, treatment, and prevention of vitamin D deficiency: an Endocrine Society clinical practice guideline. J Clin Endocrinol Metab 96, 1911-1930.

27. Elamin MB, Abu Elnour NO, Elamin KB, et al. (2011) Vitamin D and cardiovascular outcomes: a systematic review and meta-analysis. J Clin Endocrinol Metab 96, $1931-1942$.

28. Lips P, Duong T, Oleksik A, et al. (2001) A global study of vitamin D status and parathyroid function in postmenopausal women with osteoporosis: baseline data from the multiple outcomes of raloxifene evaluation clinical trial. J Clin Endocrinol Metab 86, 1212-1221. 